\title{
VARIABILITY IN THE NATURAL TERMITE RESISTANCE OF PLANTATION TEAK WOOD AND ITS RELATIONS WITH WOOD EXTRACTIVE CONTENT AND COLOR PROPERTIES
}

\author{
Ganis Lukmandaru ${ }^{1}$
}

\begin{abstract}
Property of natural termite resistance of teak (Tectona grandis) wood signifies one of its most important characteristics. With the purpose of understanding the variation in such resistance, four teak trees in the form of trunk (stem) from Randublatung, Central Java were randomly selected, and each wood portion sampled in radial and axial direction. Extractive content and color properties of the teak wood were also measured and correlated with properties of its natural termite resistance. Bioassay test was conducted by no-choice feeding method using Reticulitermes speratus Kolbe termites. The extractive contents were determined by successive extraction using $n$-hexane, ethyl acetate, and methanol, respectively. Color properties were measured with the CIELAB system. Results showed that antitermitic activity of the teak wood was affected by radial and axial position in the corresponding tree. The wood from middle part of the trees in axial direction exhibited the most resistant to termites (mean mass loss $=1-4 \mathrm{mg}$ ), while in radial direction the sapwood exhibited the least resistance (greatest mass loss), and moving inward to the near-pith heartwood the resistance tended to decrease somewhat (slight increase of mass loss). Heartwood and sapwood part differed significantly in ethyl acetate and methanolsoluble extractive contents. Apparently, the greater the ethyl-acetate-soluble extractives (EEC) then the higher the termite resistant (lower mass loss), and conversely the greater the methanolsoluble extractive (MEC) then the lower the termite resistant (greater mass loss). The brightness index $\left(\mathrm{L}^{*}\right)$ and redness index $\left(\mathrm{a}^{*}\right)$ varied significantly in radial direction, however, no significant variation was found in color properties within the heartwood. No strong degree correlation was measured between the mass loss due to termite activity and extractive content parameters. In both heartwood and sapwood, a significant negative correlation $(r=-0.50)$ was found between the mass loss and redness $\left(\mathrm{a}^{*}\right)$, while correspondingly a significant positive correlation $(r=+0.54)$ occurred between brightness and mass loss. These occurring phenomena strongly suggested that the red colored teak wood was brought about by the moderately polar EEC (e.g. tannin, quinone, and other polyphenol) that inflicted teak-wood resistance against termite (lower mass loss), while the bright-colored teak wood was due to the highly polar MEC (e.g sugar and other soluble carbohydrate) which were conversely responsible for lowering termite resistance (greater mass loss).
\end{abstract}

Keywords : Tectona grandis, termite resistance, mass loss, extractive content, color properties

\footnotetext{
${ }^{1}$ Department of Forest Product Technology, Faculty of Forestry, Gadjah Mada University; Jl. Agro No. 1, Bulaksumur, Sleman, Jogja. Email : ganisarema@lycos.com
} 


\section{INTRODUCTION}

Teak presents a highly commercial species in Indonesia, particularly in the island of Java. One of the most important characteristics is its resistance to termites due to the existence of toxic extractives in its corresponding wood. Besides affording the natural resistance against termite, accompanied with its beautiful grain appearance, teak wood is famous with golden brown color, and the wood with darker color regarded as more valuable. Therefore, the teak timber is widely used in sawing, veneer, decoration, and furniture.

Some researchers who studied within-tree variation in teak wood regarding its termite resistance used the base part of the teak tree from the pith outward at a given height (Da Costa et al., 1958; 1961; Rudman et al., 1967). With respect to the tree height, only the limited information was found. In relevant, this paper was a part of our parallel work (Lukmandaru and Takahashi, 2008), and attempts to find out the variation in properties of natural resistance of teak wood against termites. As extractive factors seemed to be related to the variation in the teak natural resistances, analysis on the extractive content was also studied. Further, it should be interesting to know how teak wood color is dependent correspondingly on intra- tree or inter-trees. Therefore, the analysis on color properties and the relationship between color and natural termite resistance were also discussed.

\section{MATERIALS AND METHODS}

\section{A. Materials}

The teak members of the 27-year-old ( 2 trees, $\mathrm{dbh}=35.1$ and $40.5 \mathrm{~cm}$ ) and 47 -year-old ( 2 trees, $\mathrm{dbh}=27.5$ and $20.5 \mathrm{~cm}$ ) from Perhutani (the State-Owned Forest Enterprise) plantation in Randublatung were sawn. The tree age effects, however, were not discussed in this study as no significant differences on any tested parameters were measured by analysis of variance (data are not shown). After sawing, the 5 -cm-thick disks were prepared from the bottom, middle, and top portions of the trees, and then air dried. The upper level corresponded to the limit of the merchantable bole. Each disk was divided into four parts: sapwood, outer heartwood, inner heartwood and near-pith heartwood. For each part, blocks were sawn on two opposite and adjacent radial faces. Each block was then cut into two pieces. One piece was used for termite resistance and colour property tests. The remaining piece was converted into wood meal (40-60 mesh size) to determine the extractive content. The meals from pieces of two opposite radii were then combined to form a single sample in order to minimize any variation between those pieces. 


\section{B. Termite resistance test}

Pine (Pinus densiflora Sieb. et Zucc.) logs containing termites (Reticulitermes speratus Kolbe) were collected in the mountain area near Tsuruoka, Yamagata (Japan) and maintained in an environmental chamber at $25^{\circ} \mathrm{C}, 75 \% \mathrm{RH}$ (relative humidity) in the laboratory until initiation of the test. For each test, an air-dried teak wood block measuring $5.0(\mathrm{~L}) \times 0.8(\mathrm{~T}) \times 0.8(\mathrm{R}) \mathrm{cm}$ was prepared and placed on the surface of the sterile sand in a plastic cup $(5.0 \mathrm{~cm} \times 6.0 \mathrm{~cm})$. The sand was moistened with distilled water regularly to retain a constant relative humidity. Fifty worker termites were added to each cup. Pine wood blocks were used as controls. This procedure was replicated three times for each sample for a total of 147 observations. The cups were stored in an environmental chamber for two weeks. The mass loss following 2 weeks from the start of the experiment was determined.

\section{Determination of Extractive Content}

Wood powder ( $2 \mathrm{~g}$ ) was successively (in stages) extracted with $n$-hexane, ethyl acetate (EtOAc), and methanol ( $\mathrm{MeOH})$ about $6 \mathrm{hr}$ for each stage in Soxhlet extractors. This staged extraction intended to fractionate or remove separately the non-polar, slightly (moderately)-polar, and highly polar components in wood extractives. After evaporating each of the solvents under reduced pressure, the extractives were removed, dried and weighed to determine the percentage of respective extractive content based on moisture-free sawdust.

\section{Color Measurement}

Wood color was measured on the wood surfaces (of the heartwood, sapwood, top, middle, and bottom portions) using an NF777 spectrocolorimeter (Nippon Denshoku Ind. Co Ltd.) with an opening diameter of $6.0 \mathrm{~mm}$ implementing CIEL ${ }^{*} \mathrm{a}^{*} \mathrm{~b}^{*}$ coordinate system. CIE standard illuminant $\mathrm{A}$, and a tungsten halogen light source were used. Percentage of reflectance data was collected at 20 -nm intervals over the visible spectrum (400-700 nm). Three measurements were made for each wood part. The value $\mathrm{L}^{*}$ describes psychometric lightness $(0=$ black to $100=$ white $)$. The value $a^{*}$ represents a color parameter on the red/green axis; a positive $\mathrm{a}^{*}$ value represents red color, whereas a negative $a^{*}$ value represents green color. The value $b^{*}$ represents a color parameter on the yellow/blue axis; a positive $b^{*}$ value represents yellow color, whereas a negative $b^{*}$ value represents blue color.

\section{E. Statistical Analysis}

The variation in the mass loss, extractive content, and color properties was analyzed using general linear models procedure by two-way (radial and axial direction factors) analysis of variance (ANOVA) followed by Duncan's multiple range test $(p=0.05)$. The relationships between the dependent variables or observed parameters (i.e. mass 
loss, extractive content, and color properties) were studied with a Pearson's correlation analysis. The effects of heartwood, sapwood, top, middle, and bottom portion on those variables were separately and jointly analyzed. All statistical calculations were conducted using SPSS-Win 10.0. (Statistical package to social sciences with Windows version).

ANOVA of the age factor was not discussed as it did not show significant differences on any tested paramaters.

\section{RESULTS AND DISCUSSION}

\section{A. Mass Loss}

In all, mean mass loss (MML) values in the heartwood area ranged from 1.2 to $19.8 \mathrm{mg}$, while in the sapwood from 2.9 to $19.6 \mathrm{mg}$. The ANOVA indicated that the interaction between axial and radial position was not significant $(p=0.46)$ in regards to MML values, while the effects of axial $(p=0.02)$ and radial positions $(p=0.01)$ were significant. Thorough examination on the MML values within radial position revealed that mass loss between the sapwood (5-12 $\mathrm{mg})$ and heartwood region $(0.1-5 \mathrm{mg})$ were significantly different (Figure 1a). In heartwood, significant difference in radial position also occurred, but it was not so significant as in the sapwood. In this regard, moving inward from the outer heartwood to the pith, the mass loss tended to increase, in that the mass loss in inner heartwood did not differed from the loss in outer heartwood. However, the mass loss in the near-pith heartwood was slightly higher than those in both inner and outer heartwood (Figure 1a). In axial position (Figure 1b), the mass loss in the middle part $(2.47 \mathrm{mg}$ ) was lower than those in the top part $(4.93 \mathrm{mg})$ and bottom part $(3.30 \mathrm{mg})$. Further, the mass loss in the top part $(4.93 \mathrm{mg})$ was higher than that in the bottom part. The mass loss in almost overall part of the teak wood (in radial and axial direction) was remarkably much lower than that in the control pine wood $(32 \mathrm{mg})$.

The obtained results indicated the heartwood with different positions in the radial direction at teak trees exhibited not-similar resistance against termite attack. It seems that the inner portion (particularly near-pith heartwood) tended to have lower termite resistance (Figure 1a). This could be attributable to greater juvenile wood portion or due to the presence of dead parenchyma cells particularly near the pith portion. These results seem to be in contradiction with earlier studies by Da Costa et al. (1958), in that an increase in natural termite resistance from inner to outer heartwood by using Nasutitermes exitious termites was not clear, although the same report also showed different results by using Coptotermes lacteous termites that supported this research results. Thus, it was thought that these differences of the resistancy might be partly due to the use of different termite species. In the case for utilization, the termite susceptibility in the sapwood ( $\mathrm{MML}=3-18 \mathrm{mg}$ ) should be noticed since the sapwood generally contains lower extractive content than the heartwood (particularly young trees). 
In the axial direction, the lowest MML values were detected in middle part of the trees (Figure $1 \mathrm{~b}$ ) indicating that the middle part exhibited the greatest resistance against termites. Further, the top portion revealed the greatest mass loss, and this could be due to the greater juvenile wood portion and lower extractive content. This is as expected as the top part is assumed to be more susceptible due to the latest formed wood which contains less toxic components (extractives). By using Coptotermes curvignathus, Febrianto et al. (2000) demonstrated that topwood of teak at various age classes was the most susceptible. With regard to decay resistance, in Thuja plicata, the resistancy has generally found to decrease with height in the tree (DeBell et al., 1999). On the other

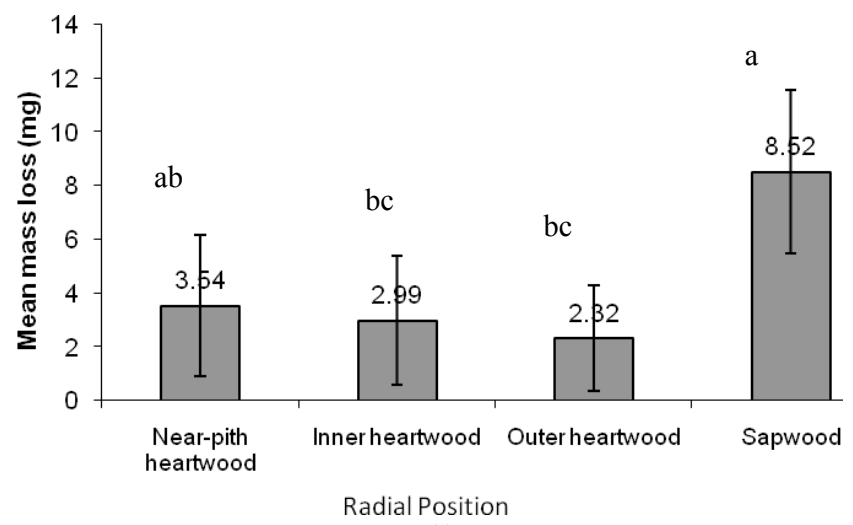

(a)

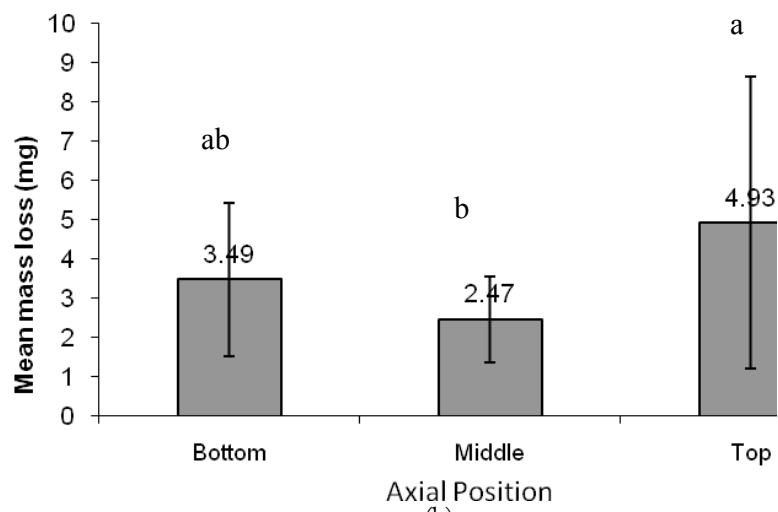

(b)

Figure 1. Figure 1a-b. Mass loss of teak wood, in radial (a) and axial (b) positions, due to the termites (Reticulitermes speratus), as observed following 2-week period from the start of experiments. The data (mean mass loss) come from 4 teak trees with mean standard deviation $\left(x\right.$ and $\left.S_{x}\right)$. Mean mass loss of the control $($ pine wood $)=$ $32 \mathrm{mg}$. The same letters on the histograms implied no significant difference in the corresponding mass loss ( $p<0.05$ by Duncan's test). 
hand, a study in Dicorynia guianensis by Amusant et al. (2004), it was found that decay resistance was greater at the top than at the base of the tree. The mass loss of teak wood in the bottom portion was slightly greater than the middle portion, but still lower than the top portion, indicating that the bottom portion was still more resistant against the termites than the top portion but less resistant than the middle portion. The possible explanation was that its extractive content (toxic compounds) was still greater than that in the top portion. Possibly, the extractive in the bottom portion experienced leaching partially due to the interference by the soil and the root system beneath the soil surface. Another possibility is due to polymerization or ageing of some toxic components in the bottom parts of the tree. That phenomenon has been observed in Eucalyptus grandis by the time a given tree is 27 years old (Nelson and Heather, 1972).

\section{B. Extractive Content}

The ANOVA revealed no significant differences were found for the interaction between radial and axial directions on such extractive contents. The average $n$-hexane (NHEC) soluble extractive content ranged about $1.5-2.4 \%$ in sapwood and about $1.8-3.7 \%$ in heartwood. However, by ANOVA, no significant differences were found for the both radial $(p=0.09)$ and axial $(p=0.83)$ directions of the trees. The extractive removed by $n$-hexane ( $n$-hexane soluble extractive) could be regarded as mostly nonpolar components (1.5-3.7\%), since $n$-hexane is virtually a non-polar solvent. Then, it could be judged that those non-polar components inflict no-toxic effect on the termites. In other words, the wood-degrading activities by the termites were not affected by the presence of non-polar extractive in teak wood.

The average ethyl acetate-soluble extractive content (EEC) ranged about consecutively $1.9-2.7 \%$ for heartwood and $0.5-0.9 \%$ for sapwood portion (Figure $2 a)$. By ANOVA, EEC levels differed significantly in both radial $(p=0.01)$ and axial $(p=0.01)$ positions. The EEC level variation among the different radial directions in the heartwood was also significant, in that the EEC levels in near-pith (1.14\%) and inner heartwood ( $1.13 \%$ ) were not significantly different from each other (Figure $2 b$ ). However, both those two EEC levels were significantly higher than in outer heartwood $(1.07 \%)$. The overall EEC levels in teak heartwood were significantly higher also than in its corresponding sapwood $(0.70 \%)$. In axial direction, the maximum EEC levels turned out to be in the middle part $(1.21 \%)$ (Figure $2 \mathrm{~b}$ ), while the EEC levels in the bottom part $(0.88 \%)$ and in the top part $(0.92 \%)$ were much lower than in the middle part. Both EEC values (top and bottom parts) were not significantly different from each other. In inward movement from the teak sapwood all the way to the near-pith heartwood, the changes in mass loss (Figure 1a) appeared to be consistent or correlated negatively with the changes in EEC levels. Likewise, in downward movement, from the top to the bottom portions, the change in mass loss seemed also consistent or correlated negatively with changes in EEC levels. Therefore, it strongly indicated that the higher EEC levels were responsible for the greater resistance of heartwood and middle portion of teak 
wood against the termite attack, and vice versa, for the lower resistance of sapwood and bottom portion of teak wood. Further, it seemed that the EEC levels at $1.05-1.21 \%$ (Figures $2 \mathrm{a}$ and $2 \mathrm{~b}$ ) inflicted significant role or efficacy on lessening the intensity of termite attack, and it was strongly assumed that the EEC contained predominantly slightly (moderately) polar components.

The average methanol-soluble extractive content (MEC) values in the heartwood varied between 3.5 and $5.0 \%$. In case of sapwood they were between 2.0 and $2.9 \%$. The ANOVA showed that a significant difference was found only for radial direction $(p<0.01)$, with the highest value for the sapwood $(4.2 \%)$ and MEC in heartwood was significantly much lower $(2.40-2.75 \%)$ (Figure $2 \mathrm{c}$ ). The variation among the different parts in the heartwood was not significant. Apparently, in inward movement the changes in mass loss (Figure 1a) were consistent or correlated positively with changes in MEC (Figure 2c). As methanol is a highly polar solvent, the MEC (2.40-4.20\%) contained predominantly highly polar component as wells. It was suspected that those highly polar components (e.g. low-molecular weight starch, sugars, and carbohydrate of shortchained polymer) as a matter of fact induced the activities of termites in attacking and degrading the teakwood (e.g. the greater the MEC, the more severe the mass loss, and vice versa).

The patterns of NHEC, EEC, and MEC differed from the general pattern of total extractive content reported by some wood chemists, which increased from sapwood to outer heartwood and then decreased toward the inner heartwood. This was because, in these research results, the extractives were fractionated into three main categories, i.e. NHEC (non-polar components such as possibly fats, waxes, resins, sterols), EEC (slightly polar component, e.g. tannins, polyphenols, stilbenes) and MEC (highly polar components, e.g. starch, sugars, soluble carbohydrate). In general, among the solvents used, the high-polar $\mathrm{MeOH}$ gave the highest level of extractive content (3.5-5.0 \%). On the other hand, EtOAc, a moderately polar solvent, removed extractives the least (0.5-2.7\%), and NHEC as the second lowest (1.5-3.7\%). Sapwood was generally found to contain more $\mathrm{MeOH}$ soluble extractives while heartwood to contain more EtOAc soluble extractives. This suggested that transformation of sapwood to heartwood was characterized by a significant increase in the amount of low-polar extractives. Previous report by Lukmandaru and Takahashi (2008) found that NHEC in the heartwood tended to increase with tree age. In this study, however, no significant difference was found with regard to NHEC value between sapwood and heartwood, as well as between bottom and top part. The comparatively high MEC values in the sapwood were in line with the tendency reported by Narayanamurti et al. (1962), Lukmandaru and Takahashi (2008).

\section{Color Properties}

Overall, by ANOVA, no significant differences were found for the interaction between radial and axial direction for color parameters of teak wood (i.e brightness, 


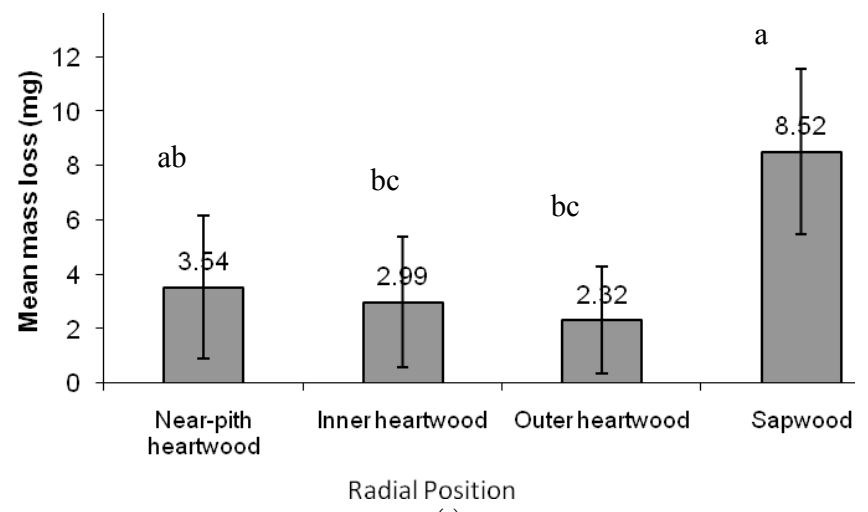

(a)

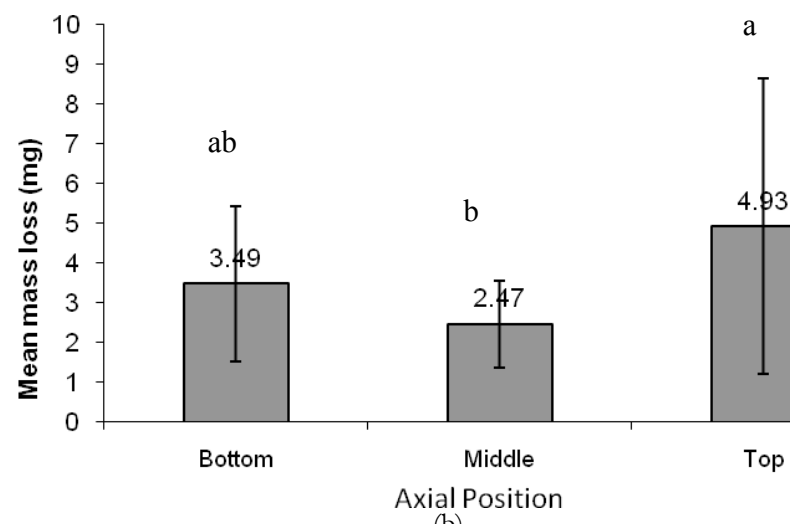

(b)

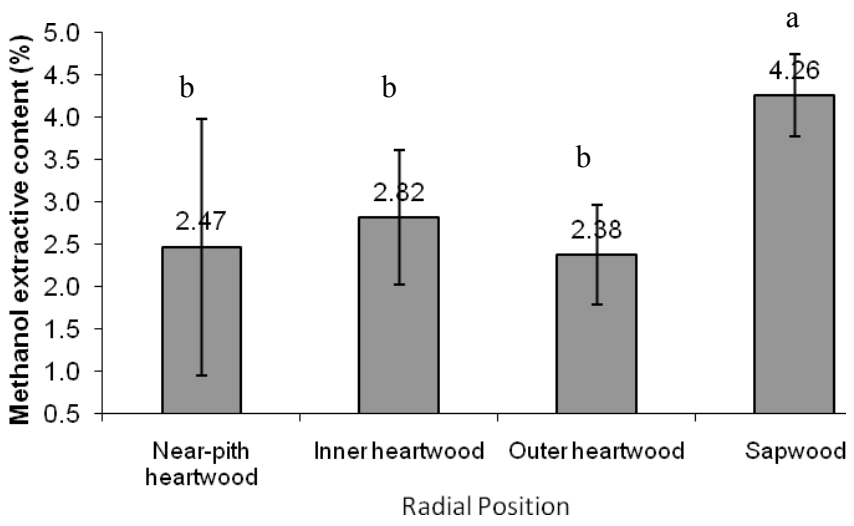

(c)

Figure 2. Ethyl acetate-soluble and methanol-soluble extractive content (\% based on oven dried mass, $\mathrm{m} / \mathrm{m}$ ) in teakwood by radial (a, c) and axial (b) position. The further remarks are similar to those in Figure 1a-b. 
redness and yellowness). The average brightness index $\left(\mathrm{L}^{*}\right)$ of the sapwood and heartwood region ranged approximately from 69 to 70 and 54 to 59 , respectively. The ANOVA revealed significant differences in the radial $(p<0.01)$ and axial $(p=0.03)$ direction. The highest brightness level was measured in the sapwood, while no significant differences were observed between radial parts in the heartwood. Further, a significantly higher average brightness index was measured in the top part of the trees (62.48) as compared to the bottom (59.54) or middle (59.46) part, as displayed in Figure 3. In all, this indicated the sapwood tended to be whiter (brighter) than the heartwood. Likewise, the top of teak wood was whiter than the bottom part. For sapwood and heartwood regions, the average redness index $\left(b^{*}\right)$ ranged from 3 to 4 and 5 to 7 , respectively. The ANOVA results showed significant difference only in the radial $(p<0.01)$ direction. Systematic differences among the different radial direction in the heartwood were not detectable, while heartwood gave significantly redder color than those in sapwood. The average yellowness index $\left(\mathrm{b}^{*}\right)$ ranged from 24 to 25 and 24 to 26 for sapwood and heartwood regions, respectively. The ANOVA results showed that no significant differences observed in both radial and axial directions.

In general, no significant differences in color properties were observed in the heartwood part. That pattern of brightness and redness indexes in this study differed from previous study in teak by Kokutse et al. (2006), Lukmandaru and Takahashi (2008), and Moya and Berrocal (2010), which found the differences between inner and outer heartwood. This indicated that variation in color properties in the heartwood from those trees in radial direction was low so that it did not necessary to sort it away and to use it separately in some applications. However, the ANOVA revealed that the wood in the top part was brighter compared to those in the bottom and middle parts, which was in agreement with the general assumption that the wood in the top part was the youngest wood. Gierlinger $e$ et al. (2004) described that variation colour heartwood was due to the oxidation and polymerization reactions that occured with wood ages. The occurring phenomena regarding the color changes in these research results indicated that

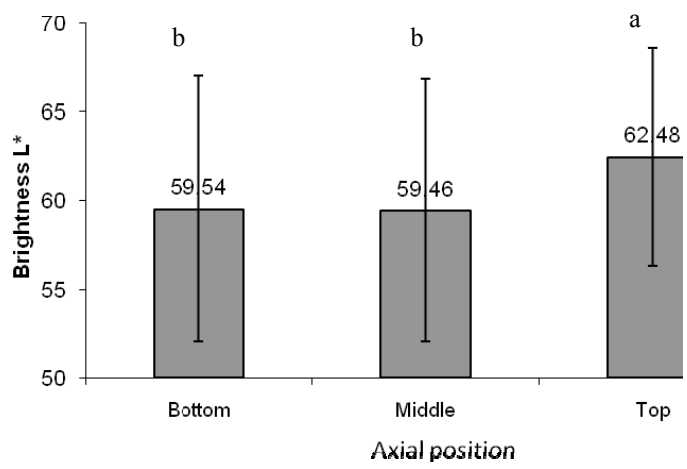

Figure 3. Color properties in $\mathrm{L}^{*}$ (brightness) of teakwood by axial position. The further remarks similar to those in Figure 1a-b and Figure 2a-c 
physiological aspect of the teak trees were involved, and as such this brought about that the older part of wood/tree (bottom and heartwood parts) contained more extractive than the younger or newly-formed wood (upper/top and sapwood parts) (Haygreen and Bowyer, 1999). Consequently, for the case of teak wood, mostly its bottom and heartwood parts were stronger in red color and brighter in white color, while its upper/ top and sapwood parts were on the contrary (weaker in red color and less bright in white color).

\section{Relationship between Termite Resistance and Extractive Contents}

Correlation analysis between mass loss and extractive content parameters in sapwood or heartwood is shown in Table 1. It confirmed that no significant correlation between the mass loss and all the extractive content parameters. This results might be due to the amounts of toxic component against termites which were weakly corrrelated to the extractive content values. Quinones and their derivatives in teak extractives, particularly tectoquinone, have been proven to be toxic to the termites (Rudman and Gay, 1961; Rudman et al., 1958; Sandermann and Simatupang, 1966). However, in natural condition, teakwood is not toxic but merely deters the termites (Da Costa et al., 1958; Rudman et al., 1967; Lukmandaru and Takahashi, 2008). Thus, this result could also be interpreted as the complex nature of teak extractives (Sandermann and Simatupang, 1966; Yamamoto et al., 1998).

If the effects of sapwood and heartwood were combined, significant correlations were measured between the mass loss and $\operatorname{EEC~}\left(r=-0.30^{*}\right)$ or $\operatorname{MEC}\left(r=0.37^{*}\right)$ (Table 1) values albeit to weak degrees. Those findings supported the extractive content analysis (Figures 3a and 3c) which that EEC and MEC values were behaved differently in sapwood and heartwood. Hence, it was suggested that the increasing of low-polar extractive content level would increase the natural termite resistance level whereas the increasing polarity of extractive content would decrease the natural termite resistance level. These occurring phenomena strongly suggested that again the moderately polar EEC (1.05-1.21\%) might contain tannin, quinone, and other polyphenol, which could be toxic or unfavorable for termites. Conversely, the highly polar MEC (2.4-4.2 \%) possibly contained sugar, short-chained starch, and soluble-carbohydrate could provide favorable food for termites. However, the extractive components of EEC and MEC were not discussed within the scope of this paper but would be interesting for further research.

\section{E. Relationship between Termite Resistance and Color Properties}

The color of wood could be associated to the quantity and type of wood extractives. Hence, it was hypothesized that heartwood color of teak might be related to natural termite resistancy. It was there easy to measure indicator for quality control. Correlation analysis (Table 1) showed the highly significant correlation was only measured between the mass loss and redness $\left(\mathrm{a}^{*}\right)$ index values in the heartwood $(r=-0.46)$. This means 
that teak was more resistant when the heartwood was redder. The relationships between the mass loss and redness are illustrated in Figure 4. Redness indexes of the heartwood samples ranged from 4.2 to 9.6 , while mass loss ranged from 1.2 to $19.6 \mathrm{mg}$. Mass loss varied considerably for samples with redness index 4.2 - 5.1, but less varied for samples with redness index between 5.9 to 9.6. Only 2 out of the 36 samples with mass loss had more than $10 \mathrm{mg}$ mass loss with redness index were 4.2 and 5.1.

If the effects of sapwood and heartwood were combined, good correlations were also found between the mass loss with brightness $(r=-0.54)$ or redness $(r=-0.50)$. That fact is expected as sapwood and heartwood were clearly distinguished in mass loss values, brightness and redness indexes. The significant negative correlation between redness and mass loss, as well as, between the EEC and mass loss (Table 1) again

Table 1. Pearson correlation coefficients $(r)$ between mass loss, extractive contents, and color properties of teak wood.

\begin{tabular}{lc}
\hline \multicolumn{1}{c}{ Parameters } & Mass loss \\
\hline Sapwood & $(r)$ \\
- n-hexane-soluble extractive content & -0.23 \\
- Ethyl acetate-soluble extractive content & -0.56 \\
- Methanol-soluble-extractive content & 0.10 \\
- Brightness color $\left(\mathrm{L}^{*}\right)$ & 0.47 \\
- Redness color $(\mathrm{a})^{*}$ & 0.03 \\
- Yellowness color $\left(\mathrm{b}^{*}\right)$ & 0.05 \\
& \\
Heartwood & \\
- $n$-hexane-soluble extractive content & 0.04 \\
- Ethyl acetate-soluble extractive content & 0.02 \\
- Methanol-soluble-extractive content & 0.16 \\
- Brightness color $\left(\mathrm{L}^{*}\right)$ & 0.34 \\
- Redness color $(\mathrm{a})^{*}$ & $-0.46^{* *}$ \\
- Yellowness color $\left(\mathrm{b}^{*}\right)$ & -0.29 \\
& \\
Heartwood and sapwood & \\
- n-hexane-soluble extractive content & \\
- Ethyl acetate-soluble extractive content & -0.16 \\
- Methanol-soluble-extractive content & $-0.30^{*}$ \\
- Brightness color $\left(\mathrm{L}^{*}\right)$ & $0.37^{*}$ \\
- Redness color $(\mathrm{a})^{*}$ & $0.54^{* *}$ \\
- Yellowness color $\left(\mathrm{b}^{*}\right)$ & $-0.50^{* *}$ \\
& -0.22 \\
\hline
\end{tabular}

Notes: for $(\mathrm{r}){ }^{*}=$ significant at $5 \%$ level; ${ }^{* *}=$ significant at $1 \%$ level 




Figure 4. Scatterplots between mass loss of teak wood against Reticulitermes speratus (as observed following two-week period from the start of experiment)

strongly suggested that the EEC (which possibly contained tannin, quinone, and other polyphenols) inflicted teak wood resistance (reduced mass loss) against termites. This was indicated that such polyphenols with their greater content in the wood were darker in color (stronger in red color). On the contrary, the brightness that correlated positively with mass loss which further correlated positively as well with MEC strongly indicated again that the MEC contained sugars, and soluble carbohydrate. With their greater content in wood they are favorable for the wood-degrading activities of termites. This is quite understandable since those carbohydrates are virtually white (bright) in color.

Earlier reports (Bhat et al., 2005; Kokutse et al., 2006; Moya and Berrocal, 2010) demonstrated that color properties could be related to decay resistance in teak heartwood. Unfortunately, no study has been conducted to correlate the native termite resistance and color properties in teak as well as in other timber species. It should be noted that this experiment did not use the native pests, therefore, the use of native termites (e.g. Coptotermes curvignathus, Neotermes tectonae) in a bioassay test is worthy for subsequent study.

\section{CONCLUSION}

Radial and axial position of wood portions in teak trees significantly affected the mean mass loss (MML $=0.5-13 \mathrm{mg}$ ) due to termite attacks. It was found that the most resistant parts (lowest mass loss) occurred at the middle wood part of teak trees. Sapwood is the most susceptible part, while in heartwood the inner the portion until the near-pith wood, then the termite resistance tended to decrease (i.e. greater mass loss).

For extractive content determination, both radial and axial directions significantly affected ethyl acetate soluble extractive content $(\mathrm{EEC}=0,5-1,9 \%)$. Methanol soluble 
extractive content $(\mathrm{MEC}=0,7-8,0 \%$ ) was affected by radial position only. Radial and axial direction did not significantly affected $n$-hexane soluble extractive content (NHEC $=0,8-6,5 \%)$.

The NHEC (as the non-polar extractive) possibly contained components such as fat, resin, and waxes. It seems that those components inflicted no effect on the wooddegrading (destroying) termite activities, judging from the non-significant correlation between mass loss and NHEC. Further, scrutinizing the negative correlation between EEC and mass loss, it is presumed that EEC contained toxic compounds (e.g. tannin, quinone, and other polyphenols), thereby inhibiting the activities of termites (decrease in mass loss). On the other hand, from the positive correlation between MEC and mass loss, it is strongly suspected that the MEC contained highly polar components (sugars and soluble carbohydrates) which are favorable to termite activities, thereby lowering wood termite-resistance.

For color properties, the axial and radial positions were significantly affected the brightness index $\left(\mathrm{L}^{*}=49-72\right)$. The brightness correlated positively with mass loss (or lower termite resistance), implying that the bright-colored teak wood contained greater percentage of-highly polar extractives (sugar and soluble carbohydrate). Further, redness index $\left(\mathrm{a}^{*}=3-9\right)$ was significantly affected by radial positions only, while yellowness index $\left(b^{*}=23-27\right)$ was independent from those factors. The redness correlated negatively with mass loss, indicating that the teak wood with more intense red color contained greater amount of moderately polar extractives (tannin, quinone, and other polyphenol) that could inhibit termite activities (reduced mass loss).

No strong significant correlation was detected between the mass loss and extractive content values (that covered NHEC, EEC, and MEC) in heartwood or in sapwood. A significant correlation was measured between the mass loss and redness index $\left(\mathrm{a}^{*}\right)$ in heartwood $(r=-0,46)$.

\section{ACKNOWLEDGEMENT}

The author wishes to express sincere gratitude to Prof. Koetsu Takahashi (Faculty of Agriculture, Yamagata University, Japan) for facilitating this research. The author is also indebted to Mr. Winanto Indriyatno and Mr. Mufti Wibowo (Brebes Forest Service) for providing the teak samples.

\section{REFERENCES}

Amusant, N., J. Beauchene, M. Fournier, G. Janin, and M.F Thevenon. 2004. Decay resistance in Dicorynia guianensis Amsh.: analysis of inter-tree and intra-tree variability and relations with wood color. Annals of Forest Science 61: 373-380.

Bhat, K.M., P.K. Thulasidas, E.J.M Florence, and K. Jayaraman. 2005. Wood durability of home-garden teak against brown-rot and white-rot fungi. Trees 19: 654-660. 
Da Costa, E.W.B., P. Rudman, and F.J. Gay. 1958. Investigations on the durability of Tectona grandis. Empire Forestry Review 37: 291-298.

Da Costa, E.W.B., P. Rudman, and F.J. Gay. 1961. Relationship of growth rate and related factors to durability in Tectona grandis.Empire Forestry Review 40: 308-319.

DeBell, J.D., J.J Morrell, and B. Gartner. 1999. Within-stem Variation in tropolone content and decay resistance of second-growth Western Redcedar. Forest Science 45: $101-107$

Febrianto, F., W. Syafii, and A. Barata. 2000. Keawetan alami kayu jati pada berbagai kelas umur. Jurnal Teknologi Hasil Hutan 13: 26-30.

Gierlinger, N., D. Jacques, M. Grabner, R. Wimmer, M. Schwanninger, P. Rozenberg, and L.E Paques. 2004. Color of larch heartwood and relationships to extractives and brown-rot decay resistance. Trees 18:102-108.

Haygreen, J.G., and J.L. Bowyer. 1999. Forest Products and Wood Science: an Introduction. Iowa State University Press, Ames, Iowa.

Kokutse, A.D., A. Stokes, H. Bailleres, K. Kokou, and C. Baudasse, 2006. Decay resistance of Togolese teak (Tectona grandis L.) heartwood and relationship with colour. Trees 20: 219-223.

Lukmandaru, G. and K. Takahashi. 2008. Variation in the natural termite resistance of teak (Tectona grandis Linn fil.) wood as a function of tree age. Annals of Forest Science 65: 708 .

Moya, R. and A. Berrocal. 2010. Wood colour variation in sapwood and heartwood of young trees of Tectona grandis and its relationship with plantation characteristics, site, and decay resistance. Annals of Forest Science 67: 109.

Narayanamurti, D., J. George, H.C. Pant, and J. Singh. 1962. Extractives in teak. Sylvae Geneticae 11: 57-63.

Nelson, N..D., and A.H. Heather. 1972. Wood colour, basic density, and decay resistance in heartwood of fast-grown Eucalyptus grandis Hill ex Maiden. Holzforschung 26: $54-60$

Rudman, P., E.W.B., Da Costa, and F.J. Gay. 1967. Wood quality in plus trees of teak (Tectona grandis L.f.): an assessment of decay and ter mite resistance. Sylvae Geneticae 16: 102-105.

Rudman, P., E.W.B Da Costa, F.J. Gay, and A.H. Wetherly. 1958. Relationship of tectoquinone to durability in Tectona grandis. Nature 181:721-722.

Rudman, P. and F.J. Gay. 1961. The causes natural durability in timber part VI. Measurement of anti-termite properties of anthraquinones from Tectona grandis L.f. by rapid semi-micro method. Holzforschung 15: 117-120. 
Sandermann, W. and M.H. Simatupang. 1966. On the chemistry and biochemistry of teakwood (Tectona grandis L.. fil). Holz Roh-Werkstoff 24: 190-204.

Yamamoto, K., M.H. Simatupang and R. Hashim. 1998. Caoutchouc in teak wood (Tectona grandis L.f.): formation, location, influence on sunlight irradiation, hydrophobicity and decay resistance. Holz Roh-Werkstoff. 56: 201-209. 